\title{
Uma Possibilidade para a Redução da Evasão em um Curso de Licenciatura em Matemática a Distância: a Proposta do GEPAM ${ }^{1}$ A Possibility to Reduce Evasion in a Distance Mathematics Degree Course: the GEPAM Proposal
}

Denise Nascimento Silveira*1 Lúcia Renata dos Santos Silveira ${ }^{1}$ Neslei Noguez Nogueira ${ }^{1}$ Rita de Cassia de Souza Soares Ramos $^{1}$

1 Universidade Federal de Pelotas. Rua Gomes Carneiro, 1 - Pelotas - RS - Brasil. *silveiradenise13@gmail.com

\section{Resumo}

O presente texto é parte de um estudo a respeito de evasão na EaD, e aborda de que forma um grupo de estudos mediado (Grupo de Estudos e Iniciação à Pesquisa na Área da Matemática - GEPAM) pode auxiliar na diminuição da evasão em um curso de Licenciatura em Matemática na modalidade a distância. Para tal, utiliza o método da Leitura Crítica, analisando textos publicados por participantes deste grupo no período de 2014 a 2018. Inicialmente, apresenta-se o curso pesquisado no contexto da Educação a Distância no País; após, situa-se a respeito da evasão na Educação a Distância; na sequência, apresenta-se a metodologia da Leitura Crítica; por último, trata-se das dinâmicas do grupo pesquisado, pontuando as falas dos participantes a respeito de sua atuação no GEPAM. Os principais resultados dizem respeito à participação dos estudantes dos grupos, na promoção de oficinas e outras atividades de iniciação à docência e de como isso influenciou os membros do GEPAM na permanência no curso. Conclui-se que o GEPAM promove por meio da colaboração, do sentimento de pertença, do aumento do rendimento acadêmico e da iniciação à docência por meio de oficinas didáticas a redução da evasão nos polos concernentes aos documentos analisados. Reafirma-se a necessidade de continuidade de projetos que envolvam estudantes na Educação a Distância, e que estudos em grupo podem diminuir a evasão e aumentar o rendimento dos alunos.

Palavras-chave: Educação matemática. Educação a distância. Grupo de estudos. Evasão.

\section{(c) (i)}

Recebido 06/08/2020 Aceito 26/11/2020 Publicado 27/11/2020
1 Este artigo é parte de um estudo a respeito da evasão em cursos de licenciatura na modalidade a Distância. Uma versão preliminar dele foi publicada na II Conferência Nacional de Educação Matemática.

\section{COMO CITAR ESTE ARTIGO}

ABNT: SILVEIRA, D. N. et al. Uma Possibilidade para a Redução da Evasão em um Curso de Licenciatura em Matemática a Distância: a Proposta do GEPAM. EaD em Foco, v. 10, n. 2, e1151, 2020. doi: https://doi.org/10.18264/eadf.v10i2.1151 


\section{A Possibility to Reduce Evasion in a Distance Mathematics Degree Course: the GEPAM Proposal}

\section{Abstract}

The current text is a part of a study about the evasion in EaD, and tells in which way a mediated studying group (Study Group and Research Initiation in Mathematics - GEPAM) can help to decrease the dropout in a Degree in Mathematics via distance learning. For this purpose, it uses the Critical Reading method, analyzing texts published by participants of this group from 2014 to 2018. Initially, the course researched in the context of Distance Education in the country is presented, after, the evasion in Distance Education is discoursed, next, the Critical Reading methodology is presented, and finally, it deals with the dynamics of the researched group, stressing the speeches of the participants regarding their performance in it. The main results pertain to the participation of the students inserted in the groups, promotion of workshops and other activities related to the initiation of teaching and how these aspects affected them to stay in the course. It is concluded that GEPAM promotes through collaboration, the feeling of belonging, the increase of academic performance and the initiation to teaching through didactic workshops to reduce dropout in the poles whose speeches were analyzed. It reaffirms the need to continue projects that involve students in Distance Education, and that studying in groups reduces evasion and increases their performance.

Keywords: Mathematical education. Distance education. Study group. Evasion.

\section{Introdução}

Este texto tem como objetivo analisar de que forma um grupo de estudos mediado (Grupo de Estudos e Iniciação à Pesquisa na Área da Matemática - GEPAM) pode auxiliar na diminuição da evasão em um curso de Licenciatura em Matemática na modalidade a distância, por meio de leitura crítica de documentos para implementar ações para possibilitar aos acadêmicos sua permanência no curso de Licenciatura. O GEPAM foi criado mediante um contexto emergente de evasão escolar e de altos índices de reprovações, com vistas a implementar ações para possibilitar aos acadêmicos sua permanência, sua persistência e consequente conclusão do curso de licenciatura. A metodologia utilizada é a Leitura Crítica de documentos, que são oriundos de pesquisas referentes à atuação do GEPAM em temas como: estudos em grupo, formação inicial de professores, Educação a Distância, e sobre o histórico do curso na instituição. Temse a expectativa de que a pesquisa relatada por meio deste artigo colabore para o desenvolvimento de propostas e investigações que tenham como finalidade minimizar a evasão e a retenção dos estudantes da Educação a Distância, pois como será exposto ao longo do texto, a evasão e a retenção são problemas que assolam essa modalidade de ensino.

Percebe-se pela leitura crítica dessas pesquisas o quanto é importante desenvolver projetos como o que aqui é descrito e a sua relevância, para os acadêmicos da Educação a Distância (EaD), como um dos caminhos que reduzem a evasão e ampliam o rendimento dos discentes e, como uma das consequências, minimizam a evasão. Com essa perspectiva, na sequência do texto, apresenta-se uma descrição a partir dos atores do curso e pesquisadores que se debruçaram sobre a constituição do CLMD na UFPel. 


\section{O CLMD no contexto da Educação a Distância no Brasil}

Desde a década de 70 do século passado, existe uma intencionalidade institucional pela criação da Universidade Aberta do Brasil (UAB), como possibilidade de EaD do Ensino Superior público no país. Segundo Costa (2012), em 1972 e 1987, o Congresso Nacional recebeu projetos de lei para instituir a Universidade Aberta do Brasil, e embora não tenha se efetivado, serviu de embrião para o reconhecimento da EaD na Lei de Diretrizes e Bases da Educação Nacional, de 1996, e a partir daí as discussões sobre a criação da UAB se efetivaram.

Abrindo caminho para que, no final de 1999, como afirma Costa (2012), 62 universidades públicas formaram um consórcio, designado por Universidade Virtual Pública do Brasil (UniRede). Tempos depois, a partir de um diálogo entre a Secretaria de Educação a Distância (SEED/MEC) e a UniRede, foram publicados editais, tendo em vista a adesão das instituições a modalidade EaD. Em 2004/2005, a UFPel participou desses editais, propiciando que ela, através do seu corpo docente, propusesse a criação do Curso de Licenciatura em Matemática a Distância.

Desde seu início, o curso foi pensado sob as necessidades dos estudantes, como afirma Dandolini et al., (2006),

o CLMD nasce conscientizado da necessidade de qualificar os processos de escolarização que compõem os cotidianos das escolas da rede pública, priorizando a formação/qualificação/atualização das práticas docentes. [...] A trajetória do nascimento do CLMD teve sua consolidação em dezembro de 2005, quando foi realizado o primeiro processo seletivo (DANDOLINI et al., 2006, p.2).

Assim, o curso de Licenciatura em Matemática na modalidade a distância se inicia em 2005, com o primeiro ingresso no ano de 2006, através do Programa Inicial de Formação de Professores Fase 1 (Pró-Licenciatura 1) tendo mais dois ingressos em 2008, mediante os programas Programa Inicial de Formação de Professores Fase 2 (Pró-Licenciatura 2) e UAB, conforme Feldkercher (2011) e Fantinel et al. (2013). Apesar dos esforços e dedicação do corpo docente pioneiro e criador do curso, a visão epistemológica do mesmo permaneceu com um formato muito próximo ao de um curso presencial, tanto na matriz curricular quanto na metodologia.

Na constituição original do CLMD, os professores atuantes eram oriundos do ensino presencial, dividindo, inclusive, sua carga de trabalho em atividades de ensino presencial e a distância. Isso fez com que as duas modalidades fossem tratadas como se tivessem as mesmas necessidades, desconsiderando suas especificidades (FANTINEL et al., 2014, p. 3074).

Tais circunstâncias, em conjunto com fatores externos, levaram a uma ruptura metodológica e organizacional do curso, então a quinta oferta, denominada UAB3 e disponibilizada para 22 polos no Rio Grande do Sul, apresentou uma estrutura diferenciada, em eixos curriculares, com um projeto pedagógico inovador. Essa reestruturação foi possível, também, pelo ingresso de professores via concurso público com vagas oriundas do projeto Universidade Aberta do Brasil, para o Centro de Educação Aberta e a Distância, que constituiu um corpo docente específico para a EaD. Tal ingresso de professores específicos para a atuação nos cursos na modalidade a distância ocorreu porque "a expansão e fortalecimento da Educação a Distância (EaD) na UFPel justificou o ingresso de novos professores no quadro efetivo da Universidade com dedicação exclusiva para a EaD" (FANTINEL et al., 2014, p. 3074). O projeto proposto pelo corpo de professores era composto por oito eixos temáticos que se interligavam e não eram necessariamente lineares, conforme Figura 1. 


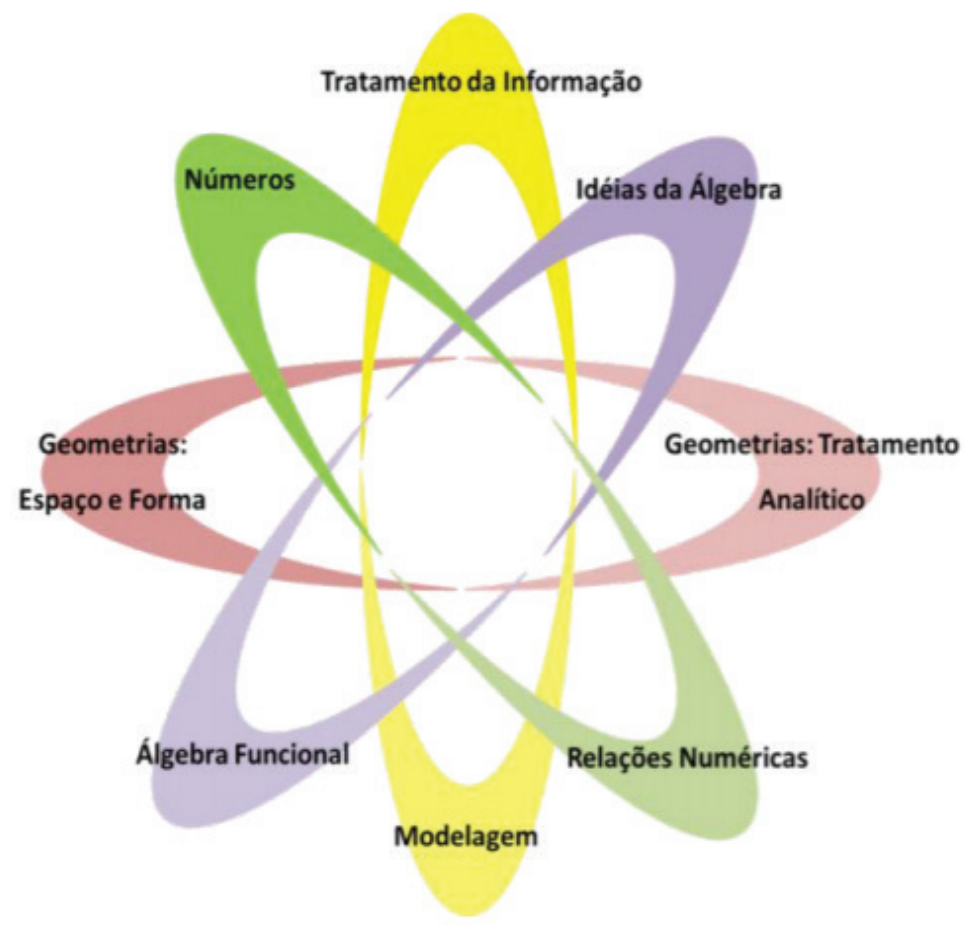

Figura 1: Eixos temáticos CLMD/CEAD/UFPel. Fonte: (FANTINEL et al., 2014).

Para além dos eixos, a constituição das práticas da equipe docente sofreu uma mudança orgânica. Segundo Salazar et al. (2013), houve uma intensificação das relações entre estudantes, tutores e professores por meio de realizações de práticas diferenciadas, como "realização de reuniões, de fóruns de discussão e grupos de estudo [...] foi instituído um encontro presencial semanal, no qual os estudantes realizam experimentos práticos relacionados aos conteúdos explorados na semana" (SALAZAR et al., 2013, p.7)

De acordo com Fantinel et al. (2014), com a contratação, via concurso público, de docentes para trabalhar exclusivamente no CLMD, este curso teve seu Projeto Pedagógico do Curso (PPC) transformado e, dessa maneira, adquiriu uma nova identidade, com características específicas para a modalidade EaD. Porém, esta proposta de currículo foi implementada em apenas duas ofertas do Curso de Matemática a Distância, a saber: UAB3 e UAB4, sendo a primeira para os 22 polos, e a segunda para 4 polos de apoio presencial. O PPC com a estrutura em eixos temáticos foi desativado em 2014. No que tange às tais mudanças do projeto político do CLMD, esclarece-se que,

o Curso de Licenciatura em Matemática a Distância teve três Projetos Políticos-Pedagógicos elaborados em um curto espaço de tempo. O primeiro que deu início ao CLMD, era muito similar ao curso presencial de Matemática da UFPel: o currículo era disciplinar e sequencial, em sistema de créditos, os professores ainda estavam vinculados ao Instituto de Física e Matemática e atuavam também no curso presencial. De acordo com SALAZAR et al. (2013), o segundo PPP foi instituído a partir da transição do CLMD para o CEAD1. Após essa transferência houve também uma reestruturação curricular. Esse novo documento trazia uma nova abordagem curricular, [...]. O terceiro PPP foi construído mediante uma discussão do primeiro PPP, ambos disciplinares, buscando valorizar especificidades da Educação a Distância (RADIN, 2015, p.54). 
Nessa caminhada, em 2014, o CLMD retornou a sua unidade de origem, o Instituto de Física e Matemática, saindo do Centro de Educação a Distância, com a oferta UAB4, e novamente com um currículo semeIhante ao do curso presencial, na oferta denominada UAB5. Uma das modificações foi a preferência dada aos professores efetivos da Universidade para a atuação no curso, não mais pela contratação via edital generalista, mas inicialmente para os professores do instituto, por indicação de departamentos, após, para professores de outros departamentos, e, na vacância, para estudantes, para somente depois abrir edital para contratação, até 2018. Tais normas criadas pela gerência da UAB na UFPel foram acatadas pelo curso, ao que Grützmann et al. (2017) afirmam que "os professores que estão atuando no curso têm sua carga horária normal na instituição e atuam no curso pela bolsa UAB/CAPES de Professor Formador" (2017, p. 1041).

Segundo Silveira et al. (2019), a respeito da equipe docente, como o curso tem uma experiência considerável, existindo há mais de 10 anos na instituição, “com um quadro de professores dedicados [...], metodologias, aparato técnico e comunicação diferenciados, esses docentes creem na necessidade transformações e/ou adaptações, tanto curriculares quanto organizacionais" (2019, p.4). Então, a partir das ofertas da UAB5 e da UAB6, em concordância com a unidade de origem do curso, o mesmo passou a ter critérios diferenciados para a seleção de docentes e, iniciou-se uma adaptação na estrutura curricular, que esteve no curso ao menos até 2018.

O CLMD tem o privilégio de atuar em polos com uma infraestrutura física e administrativa de qualidade, com equipes capacitadas. O vínculo profissional e afetivo construído, e que a cada dia é renovado, é algo para se orgulhar. Trabalhar de forma séria e competente num cenário de desgaste como é o da educação de forma geral em nosso país é um fator a ser comemorado (GRÜTZMANN et al., 2017, p. 1041).

Os polos de apoio presencial são gerenciados pelas prefeituras, em conjunto com a CAPES, por meio da UAB e em consonância com as normativas das Universidades e demais instituições. Formam uma rede interdependente que permite aos estudantes uma vivência universitária. Além da estrutura física, é nos polos de apoio presencial que os tutores presenciais atuam junto aos estudantes e também nos polos que eles se reúnem, tanto para as aulas, webconferências e trabalhos curriculares, como para os grupos de estudo. Na sequência é exposta a Figura 2, a qual apresenta um mapa com polos do CLMD, até o ingresso da UAB 4. Na descrição da Figura 2, os pontos indicam os polos, conforme a entrada. Em azul escuro, os polos da entrada Pró-Licenciatura Fase 1; em azul claro, Pró-Licenciatura Fase 2; em roxo, UAB 1; em amarelo, UAB2; em vermelho, UAB3; em verde, a UAB 4, conforme legenda descrita por Pinto (2018). É importante salientar que em alguns polos ocorreram mais de uma oferta, como é o caso de Arroio dos Ratos, que ofertou turmas nas entradas UAB 1, UAB 2 e UAB 4, por exemplo. 


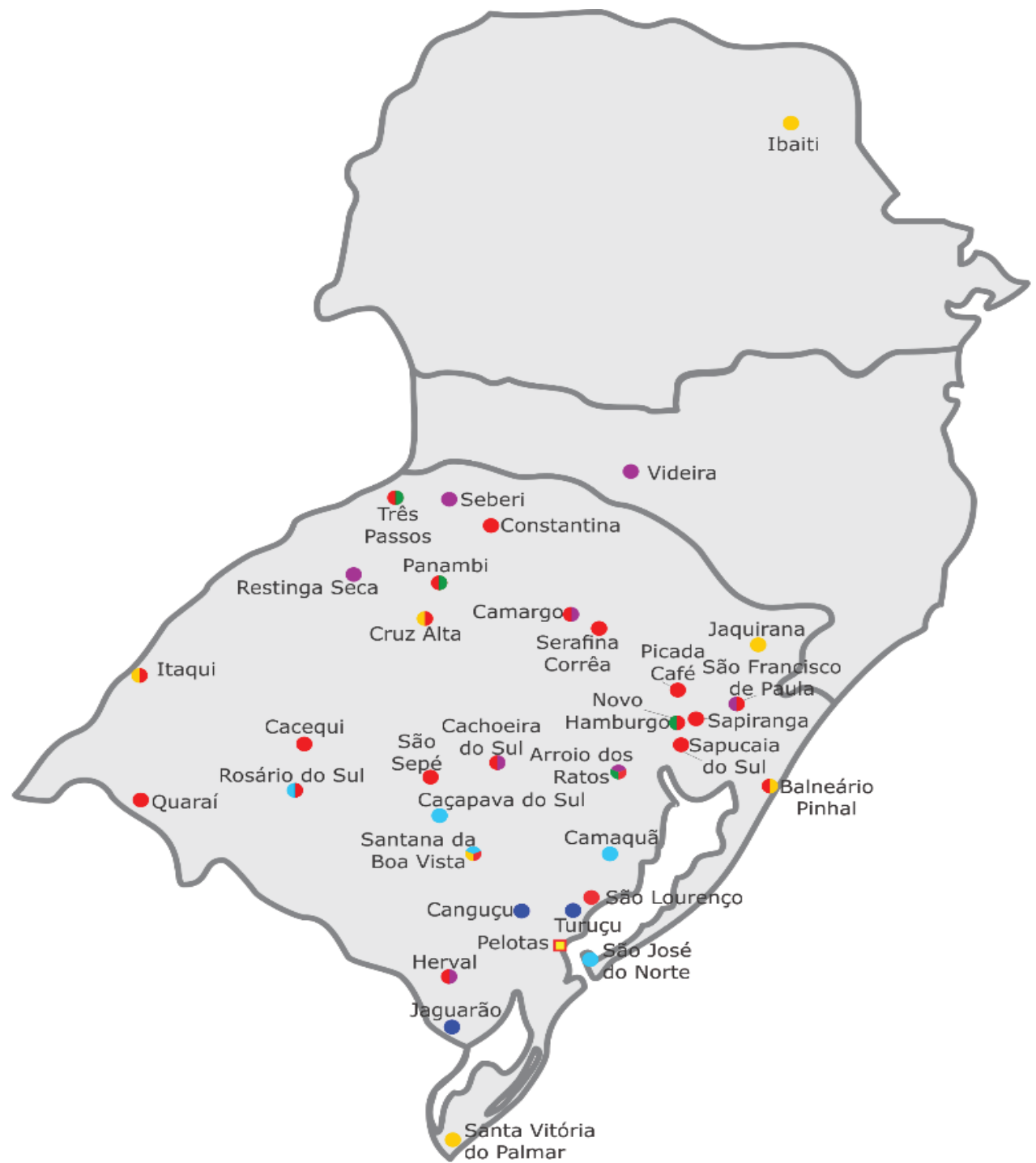

Pró-Licenciatura Fase 1

Turuçu, Canguçu e Jaguarão

Pró-Licenciatura Fase 2:

Caçapava, Camaquã, Rosário do Sul,

Santana da Boa Vista e Săo José do Norte.

O uab 1:

Arroio dos Ratos, Camargo, Cachoeira do Sul, Herval,

Restinga Sêca, São Francisco de Paula, Seberi e Videira/SC.

UAB 2 : Balneário Pinhal, Cruz Alta, Ibaiti/PR, Itaqui, Jaquirana,

Santa Vitória do Palmar e Santana da Boa Vista.
UAB 3: Arroio dos Ratos, Balneário Pinhal, Cacequi, Cachoeira do Sul, Camargo, Constantina, Cruz Alta, Herval, Itaqui, Novo Hamburgo, Panambi, Picada Café, Quaraí, Rosário do Sul, Santana da Boa Vista, São Francisco de Paula, Săo Lourenço do Sul, São Sepé, Sapiranga, Sapucaia do Sul, Serafina Corrêa e Três Passos.

UAB 4: Arroio dos Ratos, Novo Hamburgo, Panambi e Três Passos.

Figura 2: Mapa dos Polos CLMD/IFM

Fonte: (PINTO, 2018, p. 35)

As transformações propostas pelos professores do CLMD levam em conta o caminho percorrido pelo curso, tanto na experiência do corpo docente quanto em dados do sistema e em pesquisas realizadas sobre o CLMD. Uma das preocupações recorrentes se refere à evasão e permanência dos estudantes no curso, sendo este um possível reflexo de uma problemática maior que envolve a Educação a Distância no país. Apontamentos acerca da evasão na EaD serão apresentadas na seção subsequente. 


\section{Sobre a Evasão na Educação a Distância}

Dentre os vários desafios a serem enfrentados pela EaD, problematiza-se, neste texto, a evasão nos cursos dessa modalidade de ensino, a qual, segundo Abbad et al. (2010) é um obstáculo recorrente para o ensino a distância. Primeiramente, expomos a forma como compreendemos a evasão na Educação, embasando-nos teoricamente em Abbad et al. (2006), entendendo que a evasão é a desistência por parte do aluno do curso ao qual estava matriculado.

Discussões acerca dos índices de evasão, tanto na EaD quanto no ensino presencial, fazem parte dos debates hodiernos e necessários para pensar a formação de professores em diferentes áreas de conhecimento, e uma das razões para esses debates permanentes relaciona-se às avaliações educacionais realizadas pelo Ministério da Educação (MEC), que levam em conta tais indicadores. Para Silva Filho et al. (2007), no que se refere ao modo de calcular os índices de evasão, esta pode ser contabilizada por duas perspectivas, a chamada Evasão anual média, que é a comparação entre a quantidade de alunos matriculados em um ano e a quantidade de alunos matriculados no ano anterior, e a Evasão total, a qual compara o número de alunos diplomados e o número de alunos ingressantes, ao final do período de integralização do curso. A evasão total de estudantes do CLMD é considerável, sendo que para Radin et al. (2016), na oferta UAB 3 foi bastante significativa, sendo a evasão total de $67,81 \%$ dos alunos matriculados.

Pesquisas como a de Abbad et al. (2006) buscam compreender o porquê dos altos índices de evasão na modalidade EaD. De acordo com Abbad et al. (2006), as razões pelas quais os discentes desistem dos cursos podem ser categorizadas em: razões endógenas e razões exógenas. Os motivos endógenos são aqueles inerentes ao ponto de vista do aluno para com o curso (professores, tutores, infraestrutura, material didático oferecido, entre outros). Já as causas exógenas referem-se a questões pessoais dos estudantes (tempo para estudar, aptidão para a profissão, atendimento do curso às suas expectativas prévias, problemas financeiros, etc.).

Bittencourt et al. (2014) está de acordo com Abbad et al. (2006), e afirma que os motivos endógenos da evasão podem ser evitados por meio de ações implementadas pelas instituições de ensino, a saber: desenvolver um programa de controle de qualidade para a seleção de tutores, ofertar cursos de formação continuada para a docência em EaD, elaborar projetos políticos pedagógicos adequados para a modalidade de ensino a distância e preparar os profissionais que trabalham com a EaD para dar suporte técnico aos discentes inexperientes. Com relação à evasão motivada por causas exógenas, não há o que as instituições possam fazer para impedi-las, pois são intrínsecas aos alunos.

No âmbito do CLMD, Radin (2015) realizou em um dos polos desse curso uma pesquisa acerca dos motivos da significativa evasão, a partir de entrevistas semiestruturadas cujos participantes foram o coordenador do curso, o coordenador do pólo, o coordenador de estágio, seis docentes, um tutor presencial, um tutor a distância e oito discentes evadidos, Os resultados obtidos por essa investigação são mostrados no Quadro 1; a seguir, classificamos tais constatações razões exógenas e razões endógenas.

Quadro 1: Motivos de desistência dos alunos em um dos polos do CLMD

\begin{tabular}{|c|c|}
\hline Razões exógenas & Razões endógenas \\
\hline $\begin{array}{l}\text { - } \quad \text { Não era o curso desejado } \\
\text { - } \quad \text { Dificuldade de conciliar atividades relativas à } \\
\text { - } \quad \text { Namília e ao trabão de que o ensino EaD não requer dedicação }\end{array}$ & 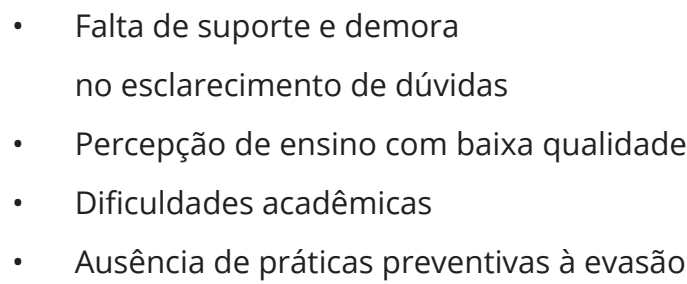 \\
\hline
\end{tabular}

Fonte: Autoria própria com base nos resultados de (RADIN, 2015) 
Conscientes dos motivos endógenos de desistência dos discentes do curso, a equipe do CLMD (alunos, tutores e professores) formou grupos de estudos, tendo como uma de suas pretensões evitar tal tipo de evasão. A criação desses agrupamentos está em sintonia com uma das propostas apresentadas por Bittencourt et al. (2014) para promover a permanência dos estudantes nos cursos de graduação, a qual

estimula a cooperação e relação entre os alunos do curso, estimulando uma criação colaborativa que dê subsídios para a aprendizagem dos alunos. Deve possibilitar um feedback ao aluno imediato de suas atividades e ações no curso. Com o devido retorno dos tutores e professores podem identificar as possíveis causas de erros nas atividades (BITTENCOURT et al. 2014, p. 475).

A ideia dos autores citados anteriormente reforça a necessidade de encontros presenciais, de integração social e intelectual para a permanência do estudante no curso EaD. A formação dos grupos de estudos em cada polo culminou na constituição de um grupo de iniciação à pesquisa, o qual é apresentado em detalhes na próxima seção.

\section{Grupo de Estudos e Iniciação à Pesquisa na Área da Matemática}

O Grupo de Estudos e Iniciação à Pesquisa na Área da Matemática - GEPAM -foi criado, segundo Silveira et al. (2019), em 2012, pela necessidade dos acadêmicos de realizarem encontros presenciais para discussão de tarefas e resolução de listas de exercícios, bem como dos relatórios e portfólios dos estágios. Curiosamente, quando foi formado, o nome do grupo não continha o termo iniciação, mas este foi sugerido pelos professores de trabalhavam com os estágios e acreditam na realização de pesquisa durante a formação inicial.

Pinto et al. (2016) explicam que o GEPAM é um grupo de pesquisa que está vinculado ao Laboratório Multilinguagens da Universidade Federal de Pelotas, o qual é constituído por alunos, professores da UFPel e membros externos que se interessam por estudar Matemática e Educação Matemática, ressaltando a afirmação de Heberle et al. (2014) de que os membros exercem diferentes papéis, como líderes, bolsistas, articuladores e participantes.

Os licenciandos do polo de Novo Hamburgo já possuíam grupos de estudos no CLMD, então solicitaram o cadastro desses grupos como Projeto de Ensino junto à Pró-Reitoria de Ensino da UFPel, o que permitiu aos acadêmicos o acesso a bolsas de estudos da universidade. Para Rosa et al. (2014), a concessão de bolsas aos discentes do CLMD aflorou neles um sentimento de pertença à comunidade acadêmica, fazendo com que muitos deles expusessem o valor que atribuíam à sua posição de bolsistas da UFPel.

Os participantes do GEPAM, a partir desse projeto, conseguiram desenvolver uma dinâmica de estudos, de construção de material instrucional, de divulgação em diferentes mídias e a produção de artigos científicos sobre as práticas que desenvolveram nesses grupos, o que os caracterizou como "grupo operativo", na perspectiva de Anzieu (2000). Segundo Ramos et al. (2017), as atividades do GEPAM colaboraram para a continuidade dos estudos dos acadêmicos, tanto na Pós-Graduação como em outros meios de formação continuada.

A atuação do grupo se deu tanto nos polos quanto na sede (Pelotas), com mediação realizada por um interlocutor, que fazia o contato entre os grupos por meio de redes sociais, como uma forma de agilizar a comunicação e a disseminação de soluções. A figura do interlocutor esteve presente até o ano de 2017. O grupo passou por adaptações e estava cadastrado até 2018 como projeto junto à Pró-Reitoria de Ensino, e o trabalho se realizava através de reuniões de estudo nos polos e organizadas pela Coordenação do CLMD. 
Trata-se, portanto, da institucionalização de uma ação proveniente dos estudantes para suprir demandas geradas em suas vivências como discentes de um curso de Licenciatura em Matemática na modalidade EaD.

\section{Metodologia}

Para compreender e discutir as estratégias que licenciandos do CLMD produziram para organizar suas demandas frente ao curso, foi feito um estudo qualitativo, de caráter descritivo, com procedimentos de pesquisa documental, baseando-nos em Gil (2008), coletando dados tanto do Projeto de Ensino cadastrado junto à Pró-Reitoria de Ensino da Universidade, além de artigos produzidos pelos membros do GEPAM, os quais estão disponíveis no repositório do Laboratório de Multilinguagens da UFPel2 , os quais estão explicitados no Quadro 2. A análise foi realizada por meio do método da Leitura Crítica, o qual consiste em supor

a capacidade de escolher as ideias principais e de diferenciá-las entre si e das secundárias. A escolha e diferenciação das ideias são feitas por meio das palavras ou expressões que as exprimem. Esse passo condiciona a posterior classificação delas em função definitivo. [...] Parte-se, portanto, de uma visão global, embora indeterminada, do texto ou livro para a operação da análise. Esta envolve os processos de diferenciação ou busca das ideias diretrizes, das ideias secundárias e seus detalhes; de compreensão ou atendimento das ideias pelo interior; de julgamento ou atribuição de valor, utilidade e importância das ideias (CERVO et al., 1983, p. 85).

Segundo Cervo et al. (1983), os procedimentos para empreender a metodologia da Leitura Crítica são:

- Identificar a ideia principal e as secundárias do documento/texto, e escolher dentre elas a que direcionará a análise desse material;

- Diferenciar e comparar as ideias entre si do documento/texto para precisar a relevância de cada uma delas, quando reunidas;

- Compreender o significado preciso dos conceitos expressos pelas ideias do material analisado;

- Avaliar o documento/texto através da Leitura Interpretativa, a qual possui três etapas, expostas na Figura 3.

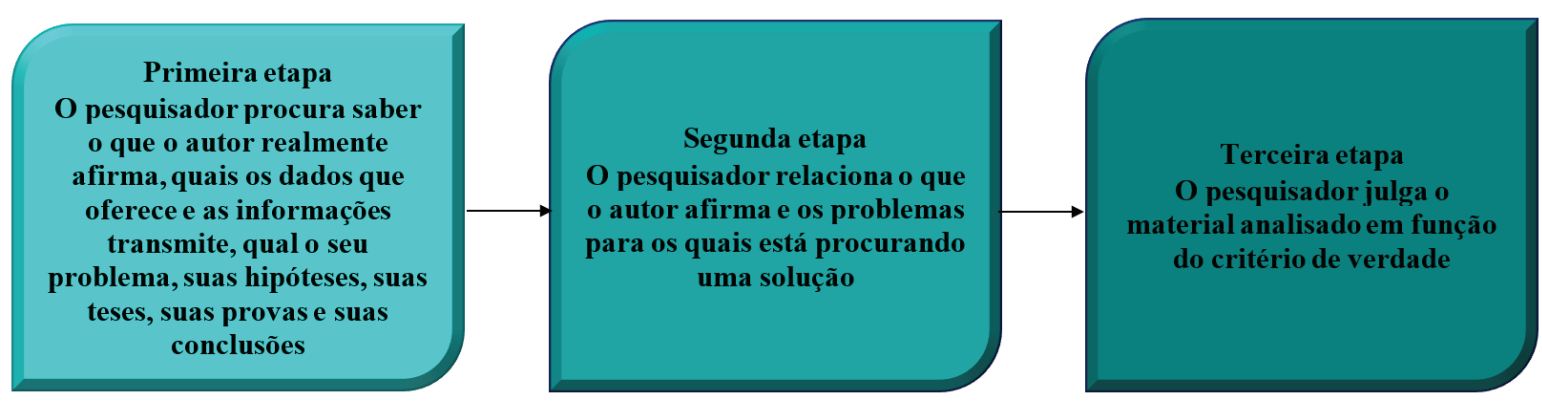

Figura 3: Etapas da Leitura Interpretativa

Fonte: Autoria própria baseada em Cervo et al. (1983)

As etapas da Leitura Interpretativa foram aplicadas nos textos encontrados no repositório do Laboratório de Multilinguagens, os quais terão alguns dos seus trechos apresentados na próxima seção deste artigo, da seguinte maneira:

2 Site do Laboratório de Multilinguagens da UFPel www.lam-ufpel.com.br. 
- Na primeira etapa, foi feita a leitura dos textos, com a finalidade de selecioná-los, tendo como critério a familiaridade do seu conteúdo com o objetivo da pesquisa exposta no presente artigo, que é de compreender como a criação do GEPAM contribuiu para a redução dos índices de evasão e de retenção no CLMD;

- Durante a segunda etapa, foi traçado um paralelo entre as teses contidas nos artigos e a fundamentação teórica utilizada pelos autores desses textos, com o propósito de verificar se tal relação foi suficiente para comprovar as afirmações expostas nos trabalhos;

- Na terceira etapa, foi dado o veredicto acerca da seleção dos artigos, enfatizando que o critério de verdade aplicado é a validação das teses defendidas pelos autores dos textos a partir de referencial teórico utilizado por eles. Dessa forma, foram escolhidos aqueles que satisfizeram as condições estabelecidas nas etapas precedentes, os quais têm alguns de seus trechos apresentados na seção denominada Discussão e resultados.

O período analisado é compreendido entre 2014 e 2018 em função da data de cadastramento do projeto junto à Universidade. Para busca dos artigos analisados, foi acessado o repositório do Laboratório Multilinguagens da UFPel, na barra publicações, e foram selecionados os textos referentes ao GEPAM. O Quadro 2 mostra os textos encontrados, entre resumos e textos completos em eventos e publicações em periódicos. Em seguida, discutiremos os resultados na seção subsequente.

Quadro 2: Trabalhos sobre o GEPAM encontrados no repositório do Laboratório de Multilinguagens

\begin{tabular}{|c|l|l|c|}
\hline $\mathrm{n}$ & \multicolumn{1}{|c|}{ Título } & \multicolumn{1}{|c|}{ Autores } & $\begin{array}{c}\text { Ano de } \\
\text { publicação }\end{array}$ \\
\hline 1 & Oficinas do GEPAM: Polo de São Lourenço do Sul & Gonçalves et al. & 2014 \\
\hline 2 & $\begin{array}{l}\text { Grupos de estudos e iniciação à pesquisa na área de matemática: } \\
\text { uma possibilidade de aprendizagem em educação a distância }\end{array}$ & Ramos et al. & 2017 \\
\hline 3 & Oficinas multilinguagens do GEPAM: Polo de São Lourenço do Sul & Gonçalves et al. & 2014 \\
\hline 4 & $\begin{array}{l}\text { GEPAM - Grupo de estudos e iniciação à pesquisa na área de } \\
\text { matemática: uma articulação de ensino e iniciação à pesquisa }\end{array}$ & Ramos et al. & 2014 \\
\hline 5 & $\begin{array}{l}\text { Grupo de Estudos e Iniciação à Pesquisa na Área de Matemáti- } \\
\text { ca: O GEPAM em São Lourenço do Sul }\end{array}$ & Gonçalves et al. & 2014 \\
\hline 6 & $\begin{array}{l}\text { GEPAM do polo de Sapucaia do Sul: a trajetória de um grupo de } \\
\text { estudos do CLMD }\end{array}$ & Lima et al. & 2014 \\
\hline 7 & $\begin{array}{l}\text { GEPAM - Grupo de estudos e iniciação à pesquisa na área de } \\
\text { matemática: uma articulação de ensino e iniciação à pesquisa }\end{array}$ & Heberle et al. & 2014 \\
\hline 8 & $\begin{array}{l}\text { GEPAM - Polo de São Lourenço do Sul: impactos do projeto } \\
\text { em 2017 }\end{array}$ & Alves et al. & 2017 \\
\hline 9 & $\begin{array}{l}\text { Impactos do GEPAM no Curso de Matemática a Distância nos } \\
\text { Anos de 2016/2017 }\end{array}$ & Silveira et al. & 2017 \\
\hline 10 & Laboratório de Multilinguagens: EGEPAM como ação de extensão & Grosser et al. & 2017 \\
\hline 11 & $\begin{array}{l}\text { GEPAM - Grupo de Estudos e Pesquisa na Área de Matemática - } \\
\text { impactos do GEPAM até 2014/O2 }\end{array}$ & Heberle et al. & 2015 \\
\hline
\end{tabular}

Fonte: Autoria própria

\section{Discussão dos resultados}

Ao pesquisar a evasão dos acadêmicos, um dos estudos mais elucidativos foi o que se realizou no polo de São Lourenço do Sul na oferta UAB 3. Radin (2015) realizou entrevistas com o corpo docente do curso e com estudantes evadidos, os quais ressaltaram que 
[...] em relação aos aspectos relacionados aos próprios estudantes, as adversidades envolvendo a conciliação de atividades pessoais com as do curso constituem-se como fortes fatores associados à desistência. Além disso, existem características, como falta de envolvimento com a graduação e hábitos de estudo insuficientes, que podem ser elementos preditores do processo de evasão no ensino a distância. Nesse cenário, reforça-se a necessidade do estabelecimento de novas práticas que visem envolver o aluno, de modo que ele sinta-se participante do processo de aprendizagem, e da prestação de orientação para criação de melhores hábitos de estudo (RADIN, 2015, p.92).

Nessa perspectiva, o GEPAM constituiu os grupos de estudos, mediando a aprendizagem, produção textual, iniciação à docência e à pesquisa, sendo assim, esse grupo desenvolve ações para reduzir os índices de evasão e de retenção por motivos endógenos, como denomina Abbad et al. (2006). Acadêmicos do mesmo polo onde ocorreu a pesquisa de Radin (2015) declararam que

o GEPAM constituiu-se no polo de São Lourenço do Sul, a partir da necessidade de um trabalho em grupo mais organizado e com assiduidade, onde os alunos tivessem para quem pedir ajuda em dúvidas referentes a atividades do eixo e dos estágios supervisionados e nas escritas dos relatos de experiências, e estudar colaborativamente os mesmos. [...]. Nesses encontros procuramos estudar as apostilas disponibilizadas no moodle, assistir vídeo aulas, quando surgiam as dúvidas, procuramos unidos respostas para tal questionamento. Também para as preparações e aplicações das atividades nos estágios supervisionados, procuramos meios que facilitasse o aprendizado dos alunos. E na escrita dos relatos de experiência procuramos em livros e artigos citações de autores que fundamentassem a escrita de cada relato. E após a avaliação dos relatos, alguns desses foram organizados e submetidos em eventos para possíveis apresentações e publicações (GONÇALVES et al., 2014c, p.3).

Declarações como essa estão presentes nos relatos de experiências dos estágios e oficinas ministradas pelos componentes do GEPAM, bem como na escrita dos portfólios de estágio. A produção textual foi incentivada, tanto pela necessidade de escrita de um relato ao final de cada disciplina de estágio, como parte da avaliação. Esse trabalho de escrita teve o objetivo de criar no estudante de licenciatura o hábito da escrita acadêmica, corroborando com a fala dos participantes ao dizer que "como resultado deste trabalho, em apenas 3 meses de trabalho, tivemos uma melhora nas avaliações dos alunos, tanto no eixo, quanto nos estágios" (GONÇALVES et al., 2014c, p.3), esta afirmação converge com a ideia de Bittencourt et al. (2014), quando a autora se refere a promoção de integração social e intelectual para a permanência do estudante no curso EaD. Ademais, PRANKE et al. (2015) concorda com Bittencourt et al. (2014), sobre a integração social e intelectual ao destacar que a elaboração de

os portfólios se mostram um potente instrumento de desenvolvimento da capacidade reflexiva e da tomada de consciência das aprendizagens realizadas, ambas necessárias para a construção da identidade docente. Por meio dos portfólios, os futuros professores puderam expressar saberes, experiências e sua subjetividade, desvelando um conhecimento sobre si, importante para sua vida profissional e pessoal (PRANKE et al. 2015, p. 93). 
A melhora da comunicação entre os estudantes é uma variável a ser levada em consideração quando se pensa na permanência desses no curso. Para Heberle et al. (2015), a análise dos resultados positivos do grupo até 2014/2, se evidenciou na "melhora no rendimento acadêmico dos participantes, [...] por meio da promoção de discussões e enquetes que levaram à sugestão de gravação de oficinas pelos membros do Laboratório Virtual Multilinguagens e essas gravações retornam para os grupos" (HEBERLE et al., 2015, p.3), assim, ao fazerem uso das diversas redes sociais, estudantes se comunicaram e trocaram informações acadêmicas e sociais. (GONÇALVES et al., 2014c) afirmam que os participantes do grupo se

organizaram e promoveram reuniões periódicas, [...]entre estes um bolsista e um líder, e ainda contaram com a ajuda de um tutor presencial, que auxiliou em questões oriundas dos estudos realizados pelo grupo, bem como contatos semanais pelas redes sociais e outras mídias, como Facebook através de uma ferramenta chamada Grupo, nesta rede social, ou Skype, com a coordenadora e com a articuladora, que auxiliaram e orientavam o grupo em suas dúvidas (GONÇALVES et al. 2014c, p. 3).

As afirmações feitas por Heberle et al. (2015) e Gonçalves et al. (2014c) vão ao encontro do que Abbad et al. (2006) afirma a respeito de quanto o sentimento de pertencer ao curso por parte do aluno contribui para a sua permanência no ambiente educacional. Tendo como intuito promover a integração dos estudantes ao curso, o CLMD desde a sua criação, utiliza diversas mídias para atuar na aprendizagem dos estudantes. Dentre elas, Silva (2016), destaca que

[...] investigando o uso do fórum e sua importância para os processos de comunicação, obtemos a declaração de uma acadêmica da UFPel, onde ela ressalta que o compartilhamento de links de vídeos é muito comum entre alunos, tutores e professores. Tais vídeos possuem conteúdo matemático e estão relacionados com os temas que estão em discussão ou representa a resolução de alguma lista de exercício (SILVA, 2016, p. 8).

Esta condição proporcionou a produção de vídeos no Laboratório Multilinguagens para os acadêmicos, com demandas provenientes do GEPAM e, com a criação e produção de vídeos para outras disciplinas e eixos do curso. A colaboração entre os estudantes foi um aspecto recorrente nos trabalhos dos componentes do GEPAM, como se pode registrar pela declaração a seguir, na qual o depoente declarou que essa forma de trabalho colaborativo

[...] teve influência nos métodos de estudos dos participantes, trouxe motivação aos pesquisados, com os resultados satisfatórios e positivos. Os dados indicados apontaram o GEPAM, como agente de aprendizagem cooperativa entre os participantes e corroboraram com a ideia do grupo ser cooperativo o que diminuiu a retenção dos estudantes de graduação (ALVES et al., 2017, p. 4).

A diminuição da retenção, ou seja, a aprovação dos estudantes, foi uma das metas do projeto, que buscou a permanência dos acadêmicos no curso, e a reunião dos estudantes em seus polos promoveu a colaboração entre os pares, o que é corroborado por Maia et al. (2004) ao afirmarem que "cursos que preveem a interação presencial entre os alunos e demais sujeitos do processo educativo propiciam a motivação para aprender e interagir, pois eles podem sentir-se incluídos em uma turma" (MAIA et al. 2004, p. 3), sendo que 
“os participantes do GEPAM indicaram que o projeto de ensino lhes ajudou principalmente o aprender, e desta forma aprovar. O trabalho em equipe na forma de união e motivação para estudar". (ALVES et al., 2017, p. 3). As ações colaborativas entre estudantes dos polos levaram a melhoria do rendimento, conforme o registro de Lima et al. (2014),

\begin{abstract}
a partir da criação do grupo, os trabalhos tiveram melhor qualidade, representados também pelos feedbacks e notas e à medida que os demais perceberam as melhorias, decidiram por ingressar no grupo. [...] a qualidade individual e em grupo melhorou consideravelmente e busca-se a qualificação e aperfeiçoamento permanentes, sempre abertos a novos integrantes (LIMA et al., 2014 p. 3).
\end{abstract}

Essa pesquisa identificou que acadêmicos que inicialmente não estavam nessa proposta de trabalho conjunto, sentiram a necessidade de fazer parte de um grupo para estudar. Essa postura foi identificada nos estudos de Rosa et al. (2014), quando publicou que "como grupo de estudos, está servindo para a promoção das rotinas, de busca pelo conhecimento e transformação de posturas, contribuindo para o hábito de colaboração entre os estudantes (ROSA et al., 2014, p. 4). Tal ideia reafirma o que diz Viel (2015), que, ao analisar a evasão de alunos de Matemática no Rio de Janeiro, comenta sobre a "tendência de estudo autônomo e organizado dos alunos, [...] apontam para uma grande predisposição de permanência neste curso devido ao estudo em grupo" (VIEL, 2015, p. 225).

O GEPAM atuou como possibilidade desse estudo organizado e de comunicação, mas também como oportunidade de estudo mediado, no qual a figura do interlocutor permite que angústias e soluções sejam compartilhadas. Percebe-se que as inquietações se assemelhavam nos diferentes polos, com estudantes oriundos de mais de 80 municípios do Rio Grande do Sul.

Embora os participantes estivessem em um curso que visa formar o professor da escola básica, presencial, o senso de comunidade online pode ser mantido no grupo, que conquanto tivesse participação online, se reunia presencialmente. Este sentido de comunidade é corroborado por Paloff e Pratt, ao falar sobre a não evasão dos alunos na modalidade a distância, quando sugerem algumas prioridades online que devem ser visadas pelo professor: "incentivar e desenvolver um sentido de comunidade, manter os alunos envolvidos com o curso e capacitar os alunos a adotar e manter o processo de construção da comunidade" (RAMOS et al. 2017, p.1382).

O estudante interlocutor era um bolsista da sede (Pelotas), que acompanhava diariamente as postagens dos líderes dos grupos em uma rede social com página específica para o GEPAM, com imagens, exercícios e material de apoio. Além do interlocutor, que era bolsista de 2014 a 2017, no período de 2014 a 2016 o projeto contou com bolsas para os líderes nos polos. A existência de um interlocutor auxilia a minimizar a desistência do curso pela razão endógena, apontada por Radin (2015), da falta de suporte e demora no esclarecimento de dúvidas. Tal questão pode ser solucionada por meio da ideia de Abadd et al. (2006), que consiste na preparação de pessoas para trabalhar com a EaD, a fim de dar suporte técnico aos discentes inexperientes. Rosa et al. (2014) explica que

os bolsistas do GEPAM cumprem 20h/a no polo, e além da organização bibliográfica e documental dos estudos semanais, pesquisam e produzem materiais instrucionais de Matemática abrangendo anos finais e também iniciais do Ensino Fundamental, bem como o Ensino Médio. A meta para cada fim de ano é a produção de pelo menos um artigo referente 
à prática do grupo de estudos na formação do acadêmico do curso de Licenciatura em Matemática a Distância e/ou de temáticas estudadas no grupo, divulgando o trabalho desenvolvido (ROSA et al., 2014, p. 4).

Além dos estudos e produção textual, os participantes organizaram oficinas didáticas, tanto para o estágio supervisionado quanto para eventos em seus polos, sendo que "as oficinas são inserções de curta duração no ambiente de construção do conhecimento, que visam instigar tanto os participantes quanto os ministrantes na busca pela melhoria da prática e da percepção matemática de mundo" (GONÇALVES et al., 2014a, p. 570).

Os alunos colocaram em ação as aprendizagens movimentadas durante o curso, na forma de oficinas, e puderam refletir sobre a própria prática com a discussão no grupo, escrita dos portfólios e dos relatos de experiência, fazendo com que ocorra a integração social e intelectual, como destaca Bittencourt et al. (2014), pois o GEPAM se propôs a "contribuir para a diminuição da evasão e da retenção dos estudantes CLMD, bem como disseminar estudos mediante oficinas didáticas". (GROSSER et al., 2017, p.4), ato reforçado pelos participantes ao dizer que

o professor precisa desenvolver suas aulas com um olhar crítico, atentando para a constante reflexão de suas práticas. Acreditamos que a participação nestas oficinas enriqueceu muito nossa formação. Quanto ao nosso aprendizado no papel de alunos-professores, percebemos como é fundamental refletir sobre as atividades e os materiais que vamos propor aos alunos, para que o objetivo das nossas aulas seja alcançado (GONÇALVES et al., 2014b, p. 367).

As reflexões e o sentir-se professor, assim como as publicações em eventos, promoveram nos estudantes diminuição da retenção e da evasão. Heberle et al., (2015) afirmam que

\begin{abstract}
diminuiu a retenção/reprovação e a evasão nos Polos assistidos pelo GEPAM e o impacto na comunidade leva em consideração a disseminação dos estudos e práticas através de oficinas de matemática e de ensino de matemática realizadas pelos participantes, assim como através de apresentações realizadas e publicadas em eventos da área, que tem apontado ser um estímulo à formação dos integrantes do Grupo, que divulgaram seus trabalhos em eventos de âmbito nacional e internacional (HEBERLE et al. 2014, p.4).
\end{abstract}

Os principais resultados podem ser resumidos pela análise feita do período 2012 - 2014 por Heberle et al. (2014), e no período de 2015 - 2017, por Silveira et al. (2017). Os primeiros afirmam que

os resultados positivos do GEPAM até 2014 se encontram na melhora no rendimento acadêmico dos participantes [...]. Também por meio da promoção de discussões e enquetes que levam à sugestão de gravação de oficinas pelos membros do Laboratório Virtual Multilinguagens, estas que retornam para os grupos para estudos como, por exemplo, oficinas de jogos e trigonometria. Algumas destas foram produzidas e levadas aos polos pelos professores do curso e por bolsistas do GEPAM e do LAM na sede (HEBERLE et al., 2014, p. 423). 
E os segundos autores defendem que

[...]a partir do levantamento dos dados, sobre os rendimentos dos estudantes envolvidos no GEPAM, nos polos de Novo Hamburgo e São Lourenço do Sul, percebeu-se que houve um aumento significativo nas médias dos estudantes após o GEPAM. Assim, corrobora-se a hipótese de que o GEPAM promoveu um impacto positivo no que se refere a um de seus objetivos, que é a diminuição da retenção de estudantes no Curso de Licenciatura em Matemática a Distância, o que já ocorrera na primeira fase do projeto, de 2012 a 2014. Com o apoio dos líderes, articulação e demais participantes, ainda com os encontros periódicos, sugere-se que os benefícios às aprendizagens dos estudantes se dão mediante o trabalho em grupo (SILVEIRA et al., 2017, p. 3).

Além dos encontros, por iniciativa dos participantes, "em 2014/02, alguns grupos realizaram o primeiro encontro na Sede com convidados que apresentaram seus relatos de experiências [...], comprovaram que diminuiu a retenção/reprovação e a evasão nos Polos assistidos pelo GEPAM". (HEBERLE et al., 2015, p.3). Tal encontro denominou-se I EGEPAM - Encontro Gaúcho do EGEPAM (SILVEIRA et al., 2017, p.1); em 2017/2, ocorreu no polo de Novo Hamburgo o II EGEPAM, com a presença de participantes de diversos polos e da sede (GROSSER et al, 2017, p.1). Após esta Discussão dos Resultados, na próxima seção, apresentam-se as Considerações Finais.

\section{Considerações Finais}

A Educação a Distância no Brasil vem sendo construída há mais de 30 anos, tendo seu início por via de Universidade Aberta do Brasil no começo deste século. O Curso de Licenciatura em Matemática a Distância foi pioneiro nessa modalidade na UFPel, atuando em conjunto com as políticas de EaD do País. Foi pensado desde o início, prevendo as particularidades da EaD, e sofreu transformações epistemológicas e organizacionais importantes durante seu percurso, e problematiza a questão da evasão, a qual é assunto recorrente na modalidade EaD.

Apesar da evasão considerável no curso, o GEPAM se insere como um projeto de ensino oportunizando a estudantes e demais participantes encontros presenciais e on-line nos quais são discutidas as tarefas, conceitos e ações e são organizadas produções textuais e oficinas didáticas, bem como outras questões relevantes para o curso. A participação no GEPAM promoveu nos discentes a aprendizagem colaborativa e o aumento do rendimento acadêmico, possibilitando a permanência do mesmo no curso. Para além do rendimento, também percebemos que os participantes do GEPAM se inseriram no meio acadêmico como estudantes cujas ações resultaram em impactos na comunidade, como oficinas didáticas e disseminação de práticas em eventos.

O período analisado (2014 - 2018) contou com o apoio da Pró-Reitoria de Ensino da Universidade, mediante bolsas de estudo para estudantes de um curso na modalidade EaD, possibilitando aos estudantes bolsistas maior dedicação ao curso e ao projeto, com produção acadêmica e desenvolvimento de ações de Educação Matemática em seus Municípios, contribuindo para a interiorização do conhecimento universitário no Rio Grande do Sul.

A respeito da evasão no curso, os relatos sobre o sentimento de pertença foram importantes, e as variáveis solidão acadêmica, baixo rendimento, pouca discussão e falta de sentido sofreram uma diminuição, percebida pelos relatos dos participantes do GEPAM dos textos analisados, levando-os à menor retenção, ao pertencimento à comunidade universitária e, consequentemente, à redução dos índices de evasão. Tais práticas são positivas e sugere-se sua continuidade. 
Esse texto é parte de uma pesquisa que busca compreender a evasão em cursos na modalidade EaD no Ensino Superior, a partir dos relatos dos estudantes. Visa também sugerir recursos e práticas que se caracterizem como apoio aos sujeitos, como grupos de estudo, mediação por pares e demais possibilidades que provenham dos próprios sujeitos. Faz-se importante e necessária a continuidade da pesquisa e a divulgação dos resultados, a fim de expor práticas possíveis para a melhoria da qualidade da Educação nas diferentes modalidades.

\section{Referências}

ABBAD, G. S.et al. Evasão em curso via internet: Explorando variáveis explicativas. RAE Eletrônica, v. 5, n. 2, p. 1676-5648, 2006. Disponível em: https://www.scielo.br/pdf/raeel/v5n2/v5n2a08.pdf. Acesso em: 10 jul. 2020.

ABBAD, G. S.et al. Panorama das pesquisas em educação a distância no Brasil. Estudos de Psicologia (UFRN), v. 15, n. 3, p. 291-298, 2010. Disponível em: https://www.scielo.br/pdf/epsic/v15n3/a09v15n3. pdf. Acesso em: 10 jul. 2020.

ALVES, L. S. et al. GEPAM: Polo São Lourenço do Sul: impactos do projeto em 2017. In: III Congresso de Ensino de Graduação, 2017, Pelotas. Anais do III Congresso de Ensino de Graduação. Pelotas: UFPel, 2017. Disponível em: http://cti.ufpel.edu.br/siepe/arquivos/2017/MD_04472.pdf. Acesso em: 12 jul. 2020.

BITTENCOURT, I. M. et al. Evasão nos cursos na modalidade de educação a distância: estudo de caso do Curso Piloto de Administração da UFAL/UAB. Ensaio: Avaliação e Políticas Públicas em Educação, v. 22, n. 83, p. 465-504, 2014. Disponível em: https://www.scielo.br/pdf/ensaio/v22n83/a09v22n83.pdf. Acesso em: 10 jul. 2020.

CERVO, A. L. et al. Metodologia cientifica para uso dos estudantes universitários. 3.ed. São Paulo: McGraw-Hill do Brasil, 1983. 249 p.

COSTA, M. L. F. História e políticas públicas para o ensino superior a distância no Brasil: o programa universidade aberta do Brasil em questão. Revista HISTEDBR, v. 12, n. 45, p. 281-295, 2012. Disponível em: http://www.histedbr.fe.unicamp.br/revista/edicoes/45/art18_45.pdf. Acesso em: 08 jul. 2020.

DANDOLINI, G. A.et al. Curso de Licenciatura em Matemática a Distância: Um Relato de Experiência. RENOTE. Revista Novas Tecnologias na Educação, v. 4, n. 1, 2006. Disponível em: http://www.cinted.ufrgs. br/renoteold/jul2006/artigosrenote/a47_21237.pdf. Acesso em: 06 jul. 2020.

FANTINEL, P. C. et al. A Formação Inicial do Professor de Matemática em Foco: a arquitetura pedagógica do CLMD/CEAD/UFPel. In: XI Congresso Brasileiro de Ensino Superior à Distância (XI ESUD), 2014, Florianópolis. Anais do XI Congresso Brasileiro de Ensino Superior à Distância, Florianópolis, 2014. Disponível em: https://www.researchgate.net/publication/280026407_A_FORMACAO_INICIAL_DO_PROFESSOR_DE_ MATEMATICA_EM_FOCO_A_ARQUITETURA_PEDAGOGICA_DO_CLMDCEADUFPel. Acesso em: 06 jul. 2020.

FANTINEL, P. C.et al. Autorregulação da Aprendizagem na Educação a Distância Online. In: XVIII Conferência Internacional sobre Informática na Educação (XVIII TISE), 2013, Porto Alegre. Anais da XVIII Conferência Internacional sobre Informática na Educação, Porto Alegre, 2013. Disponível em: http:// www.tise.cl/volumen9/TISE2013/146-154.pdf. Acesso em: 06 jul. 2020.

FELDKERCHER, N. O estágio na formação de professores presencial e a distância: a experiência do curso de matemática da UFPel. 2011. Dissertação (Mestrado em Educação) - Faculdade de Educação, Universidade Federal de Pelotas, Pelotas.

GIL, A. C. Como elaborar projetos de pesquisa. São Paulo: Atlas, 2008. 176 p. 
GONCALVES, E. S. et al. Grupo de Estudos e Iniciação à Pesquisa na Área de Matemática: O GEPAM em São Lourenço do Sul. In: CIC - Congresso de Iniciação Científica da UFPel, 2014, Pelotas. Anais do CIC Congresso de Iniciação Científica da UFPel. Pelotas: UFPel, 2014a. Disponível em: http://cti.ufpel.edu. br/siepe/arquivos/2014/MD_01704.pdf. Acesso em: 08 jul. 2020.

GONÇALVES, E. S. et al. Oficinas do GEPAM: Polo de São Lourenço do Sul. In: EREMATSUL, 2014, Bagé. Anais do EREMATSUL. Bagé: UNIPAMPA, 2014b. Disponível em: https://eventos.unipampa.edu.br/eremat/files/2014/12/RE_GONCALVES_00900417048.pdf. Acesso em: 08 jul. 2020.

GONÇALVES, E. S. et al. Oficinas multilinguagens do GEPAM: Polo de São Lourenço do Sul. In: Congresso de Extensão e Cultura, 2014, Pelotas. Anais do Congresso de Extensão e Cultura: memórias de muitos tempos. Pelotas: UFPel, 2014c. Disponível em: https://eventos.unipampa.edu.br/eremat/files/2014/12/RE_GONCALVES_00900417048.pdf. Acesso em: 08 jul. 2020.

GROSSER, A. P. et al. Laboratório Multilinguagens: GEPAM como ação de extensão. In: IV Congresso de Extensão e Cultura, 2017, Pelotas. Anais do IV Congresso de Extensão e Cultura. Pelotas: UFPel, 2017. Disponível em: http://cti.ufpel.edu.br/siepe/arquivos/2017/XE_05093.pdf. Acesso em: 08 jul. 2020.

GRÜTZMANN, T. P. et al. As relações construídas com os polos no Curso de Licenciatura em Matemática a Distância. In: XIV Congresso Brasileiro de Ensino Superior a Distância. 2017, Rio Grande. Anais do XIV Congresso Brasileiro de Ensino Superior a Distância. Rio Grande: FURG, 2017. p. 1034 - 1043. Disponível em: https://esud2017.furg.br/images/arquivos/ANAIS_ESUD2017_final.pdf. Acesso em: 09 jul. 2020.

HEBERLE, A. G. P. et al. GEPAM - Grupo de Estudos e Pesquisa na Área de Matemática: uma articulação de ensino e iniciação à pesquisa. In: EREMATSUL, 2014, Bagé. Anais do EREMATSUL. Bagé: UNIPAMPA, 2014. Disponível em: https://eventos.unipampa.edu.br/eremat/files/2014/12/PO_HEBERLE_38826631034.pdf. Acesso em: 09 jul. 2020.

HEBERLE, A. G. P. et al. GEPAM - Grupo de Estudos e Pesquisa na Área de Matemática - impactos do GEPAM até 2014/02. In: CEG - Congresso de Ensino de Graduação, 2015, Pelotas. Anais do CEG - Congresso de Ensino de Graduação. Pelotas: UFPel, 2015. Disponível em: https://eventos.unipampa.edu.br/eremat/files/2014/12/PO_HEBERLE_38826631034.pdf. Acesso em: 09 jul. 2020.

LIMA, G. P. et al. GEPAM do polo de Sapucaia do Sul: A trajetória de um grupo de estudantes do CLMD. In: CIC - Congresso de Iniciação Científica da UFPel, 2014, Pelotas. Anais do CIC - Congresso de Iniciação Científica da UFPel. Pelotas: UFPel, 2014. Disponível em: http://cti.ufpel.edu.br/siepe/arquivos/2014/MD_02726.pdf. Acesso em: 09 jul. 2020.

MAIA, M. C. et al. Análise dos Índices de Evasão nos Cursos Superior a Distância do Brasil. 2004. Disponível em: https://www.researchgate.net/publication/266023475_Analise_dos_indices_de_evasao_nos_ cursos_superiores_a_distancia_do_Brasil. Acesso em: 14 jul. 2020.

PINTO, A. C. M. Constituição da docência no Curso de Licenciatura em Matemática a Distância da Universidade Aberta do Brasil (UAB): Um itinerário formativo. 2018. Dissertação (Mestrado em Ensino de Ciências e Matemática) - Programa de Pós-Graduação em Ensino de Ciências e Matemática, Universidade Federal de Pelotas, Pelotas.

PINTO, S. P. W. et al. Laboratório Multilinguagens da UFPEL - uma experiência interligando ensino, pesquisa e extensão. In: XII Encontro Nacional de Educação Matemática, 2016, São Paulo. Anais do XII Encontro Nacional de Educação Matemática. São Paulo, 2016. Disponível em: http://www.sbem.com. br/enem2016/anais/pdf/8369_4350_ID.pdf. Acesso em: 08 jul. 2020.

PRANKE, A. et al. Formação inicial de professores em Matemática a Distância: o portfólio como instrumento de reflexão nos estágios. Educação em Revista (UNESP. MARÍLIA), v. 16, n. 2, p. 83-96, 2015. Disponível em: http://revistas.marilia.unesp.br/index.php/educacaoemrevista/article/view/5477. Acesso em: 07 jul. 2020. 
RADIN, M. M. T. Limites da EAD para a materialização do direito à educação: estudo sobre a evasão em um polo do Curso de Licenciatura em Matemática a Distância da Universidade Federal de Pelotas. 2015. Dissertação (Mestrado em Política Social) - Programa de Pós-Graduação em Política Social, Universidade Católica de Pelotas, Pelotas.

RADIN, M. M. T.; LESTON, S. S.; CUNHA, M. S. Limites da EAD para a materialização do direito à educação: um estudo sobre a evasão. Práxis Educacional, v. 13, n. 24, p. 55-75, 2016. Disponível em: http://periodicos2.uesb.br/index.php/praxis/article/view/929/792. Acesso em: 06 jul. 2020.

RAMOS, R. C. S. S. et al. GEPAM: Grupo de estudos e iniciação à pesquisa na área de matemática: uma possibilidade de aprendizagem em educação a distância. In: III Congresso Internacional de Educação Superior a Distância, 2017, Rio Grande. Anais do III Congresso Internacional de Educação Superior a Distância, 2017. p. 1373-1385. Disponível em: https://esud2017.furg.br/images/arquivos/ ANAIS_ESUD2017_final.pdf. Acesso em: 06 jul. 2020.

ROSA, C. B. et al. GEPAM - Grupo de Estudos e Pesquisa na Área de Matemática: uma articulação de ensino e iniciação à pesquisa. In: CIC - Congresso de Iniciação Científica da UFPel, 2014, Pelotas. Anais do CIC - Congresso de Iniciação Científica da UFPel. Pelotas: UFPel, 2014. Disponível em: http://cti.ufpel. edu.br/siepe/arquivos/2014/MD_01704.pdf. Acesso em: 03 jul. 2020.

SALAZAR, S. B. et al. A História em Construção do CLMD/CEAD/UFPel a Partir do Núcleo Docente Efetivo. In: X Congresso Brasileiro de Ensino Superior à Distância, 2013, Belém. Anais do X Congresso Brasileiro de Ensino Superior à Distância, Belém, 2013. Disponível em: https://docplayer.com.br/ 12599921-A-historia-em-construcao-do-clmd-cead-ufpel-a-partir-do-nucleo-docente-efetivo.html. Acesso em: 02 jul. 2020.

SANTOS, S. C. A problemática da evasão em uma licenciatura em matemática a distância: a compreensão dos alunos iniciantes. In: Simpósio Internacional de Educação a Distância, 2014, São Carlos. Anais do Simpósio Internacional de Educação a Distância. São Carlos, 2014. Disponível em: http://www.sied -enped2014.ead.ufscar.br/ojs/index.php/2014/article/view/636/367. Acesso em: 03 jul. 2020.

SILVA FILHO, R. L. et al. A evasão no ensino superior brasileiro. Caderno de Pesquisa, v. 37, n. 132, p. 641-659, 2007. Disponível em: https://www.scielo.br/pdf/cp/v37n132/a0737132.pdf. Acesso em: 12 jul. 2020.

SILVA, S. R. P. A produção de vídeos no Estágio Supervisionado em um curso de Matemática a Distância. In: XX EBRAPEM - Encontro Brasileiro de Estudantes de Pós Graduação em Educação Matemática, 2016, Curitiba. Anais do XX EBRAPEM - Encontro Brasileiro de Estudantes de Pós Graduação em Educação Matemática, Curitiba, 2016. Disponível em: http://www.ebrapem2016.ufpr.br/wp-content/ uploads/2016/04/gd6_sandro_silva.pdf. Acesso em: 05 jul. 2020.

SILVEIRA, L. R. S. et al. Impactos do GEPAM no Curso de Matemática a Distância nos Anos de 2016/2017. In: III Congresso de Ensino de Graduação, 2017, Pelotas. Anais do III Congresso de Ensino de Graduação. Pelotas: UFPel, 2017. Disponível em: http://cti.ufpel.edu.br/siepe/arquivos/2017/MD_04570.pdf. Acesso em: 06 jul. 2020.

SILVEIRA, L. R. S. et al. GEPAM como alternativa para a diminuição da evasão e da retenção em um Curso de Licenciatura em Matemática EaD. In: II Conferência Nacional de Educação Matemática, 2019, Taquara. Anais da II Conferência Nacional de Educação Matemática, Taquara, 2019. Disponível em: https://www2.faccat.br/portal/sites/default/files/65\%20CO.pdf. Acesso em:03 jul. 2020.

SOUZA, J. A. et al. Curso de Licenciatura em Matemática a Distância - Uma Síntese do Projeto Pedagógico. RENOTE. Revista Novas Tecnologias na Educação, v. 3, n.1, 2005. Disponível em: http://www.cinted. ufrgs.br/renoteold/maio2005/artigos/a45_cursomatematica.pdf. Acesso em: 05 jul. 2020. 
VIEL, S. R. Um Olhar Sobre a Formação de Professores de Matemática a Distância: o caso do CEDERJ/ UAB. 2011. 218 f. Tese (Doutorado em Educação Matemática) - Instituto de Geociências e Ciências Exatas, Universidade Estadual Paulista, Rio Claro, 2011. 